\title{
Decreased Level of Epidermal Growth Factor in Milk from Diabetic Rats
}

\author{
JESPER THULESEN, EBBA NEXØ, LASSE RAABERG, AND STEEN SEIER POULSEN \\ Institute of Medical Anatomy, University of Copenhagen. The Panum Institute. Blegdamsvej 3, 2200 \\ Copenhagen, Denmark [J.T., L.R., S.S.P.J; and Department of Clinical Chemistry, University Hospital of \\ Aarhus, 8000 Aarhus, Denmark [E.N.]
}

\begin{abstract}
Experimental diabetes was induced in rats with streptozocin before mating, and the influence of diabetes on epidermal growth factor (EGF) in milk and on other milk components was studied. Throughout the lactation period, a significant decrease was found both in the production of milk and in the concentration of EGF in milk from untreated diabetic rats compared with an insulintreated diabetic group and a control group. Thus, the total output of EGF in milk from diabetic rats was considerably decreased. The concentrations of total protein and haptocorrin, a cobalamin (vitamin $B_{12}$ )-binding protein, and the content of fat, however, were unaltered by diabetes. Therefore, the decrease in milk EGF seemed to be selective compared with total protein in milk. The pups of diabetic dams had reduced body weights within 1 wk of lactation and reduced body lengths on d 16 of lactation compared with control pups. Furthermore, the time of eyelid opening was delayed, but no difference in the time of tooth eruption was observed. Insulin-treatment of diabetic rats restored the milk volume and the EGF concentration to values comparable to those of the controls. Pups of the insulintreated diabetic dams were comparable to the pups of the controls. These results indicate that insulin deficiency in lactating rats causes a decrease in the lactational performance and in the EGF content of milk. (Pediatr Res 35: 107-111, 1994)
\end{abstract}

\section{Abbreviations}

EGF, epidermal growth factor

Neonatal problems are frequently encountered in infants of diabetic mothers, but they can be reduced by strict maternal metabolic control during pregnancy $(1,2)$. A reduction in the milk production of diabetic mothers has been reported (3), but little is known about the composition of the milk.

High concentrations of growth factors such as EGF are present in milk from various species, including man (4-7). EGF is a mitogenic polypeptide consisting of 53 amino acid residues. Among others, it is synthesized in the mammary glands (8) and it is known to be a major growth-promoting agent in milk $(7,9)$. EGF has been shown to accelerate eyelid opening and tooth eruption in newborn rats (10), and it promotes maturation of the gut $(11,12)$ and the lungs $(13)$.

Received March 18, 1993; accepted September 2, 1993.

Correspondence and reprint requests: Jesper Thulesen, Institute of Medical Anatomy, Dept. B, University of Copenhagen, The Panum Institute, Blegdamsvej 3, 2200 Copenhagen N, Denmark.

Supported by The Danish Biotechnology Center for Signalpeptide Research, The Danish Medical Research Council (12-0558-1, 12-0303-2), and The Danish The Danish Medical Resear
Cancer Society $(91-026)$.
Recently, experimentally induced diabetes has been shown to affect the production of EGF and the number of EGF receptors in several organs (14-18). In diabetic mice, the synthesis of EGF in the submandibular glands is impaired $(14,15)$, and in diabetic rats a decrement in the number of EGF receptors in hepatocytes (16) and in placenta has been reported (17). Also, the function of the EGF system seems to be influenced by diabetes, inasmuch as autophosphorylation of the EGF receptor is reduced (18). It is not known, however, whether diabetes results in a decrease in the content of EGF in milk, which might be a cause for changes in the neonatal development. This prompted us to examine the contents of EGF, total protein, the cobalamin (vitamin $B_{12}$ )binding protein haptocorrin, and fat in milk from rats with experimentally induced diabetes and to observe the postnatal maturation of the pups during the lactation period.

\section{MATERIALS AND METHODS}

Animals. Female nullipara Wistar rats weighing 220-240 g were randomly allocated into three groups: 1 ) diabetic, insulintreated during pregnancy but untreated during lactation; 2) diabetic, insulin-treated during pregnancy and lactation; and 3) a control group.

Each group contained at least 10 dams, and the litters were adjusted to 12 pups. All animals were allowed free access to water and laboratory food (Altromin no. 1314, Lage, Germany). Light-dark cycles of $12 \mathrm{~h}$ each were maintained in the animal holding room. The day of parturition was considered the first day of lactation.

Experimental diabetes. Diabetes was induced before the rats were mated by a single injection i.p. of $60 \mathrm{mg} / \mathrm{kg}$ streptozocin (Sigma Chemical Co., St. Louis, MO) dissolved in freshly prepared $50 \mathrm{mM}$ citrate buffer ( $\mathrm{pH} 4.0$ ). Control animals received an equivalent volume of citrate buffer. Only rats with a blood glucose concentration above $20 \mathrm{mmol} / \mathrm{L}$ and glucosuria $24 \mathrm{~h}$ after the streptozocin injection were included in the diabetic groups and placed in cages with male Wistar rats until the appearance of a vaginal plug. The diabetic rats were treated to normoglycemia with a long-acting heat-treated insulin preparation (Ultralente, $\mathrm{pH}$ 5.5, Novo-Nordisk, Bagsvaerd, Denmark) (19) during pregnancy, and one group was also treated during the lactation period. Injections of insulin were given at $1600 \mathrm{~h}$. Maternal blood glucose concentrations were measured by the glucose oxidase method with a One Touch II (Lifescan, Milpitas, CA) each morning. Glucose in the urine was measured with Keto-Diabur-Test 5000 stix (Boehringer-Mannheim, Mannheim, Germany).

Milk samples. Milk was obtained on d 1, 6, 16, and 21 of lactation. Four $\mathrm{h}$ before milking, the sucklings were separated from the dams. The mothers were milked (6) under light barbiturate anesthesia (Brietal $50 \mathrm{mg} / \mathrm{kg}$ i.p., Metohexital, Eli Lilly, Indianapolis, IN). The milk ejection was stimulated by admin- 
istration of 1 IU Syntocinon s.c. (Oxytocin, Sandoz, Basel, Switzerland). A milking session lasted $45 \mathrm{~min}$ per rat. The milk was immediately centrifuged at $25000 \times g$ for $30 \mathrm{~min}$ at $4^{\circ} \mathrm{C}$. The fat was removed and the rest was centrifuged for an additional $30 \mathrm{~min}$ at $25000 \times \mathrm{g}$. The whey fraction was then recovered by aspiration. Trasylol (Aprotinin, Bayer, Leverkusen, Germany) $500 \mathrm{kIU}$ per $\mathrm{mL}$ was added, and the samples were stored at $-20^{\circ} \mathrm{C}$.

Development of pups. The pups were observed daily for incisor eruption and eyelid opening. Their weight and head-to-tail length were measured on $\mathrm{d} 1,6,16$, and 21 .

Laboratory analyses. EGF was quantified in milk samples with an ELISA as described by Jørgensen et al. (20). Milk proteins were measured by the Pierce bicinchoninic acid method (21). The unsaturated cobalamin-binding capacity was determined using cyano- $\left[{ }^{57} \mathrm{CO}\right]$ cobalamin $(11.2 \mathrm{~Bq} / \mathrm{fmol}$ ) (Amersham International, Buckinghamshire, UK) and hemoglobin-coated charcoal as described by Gottlieb et al. (22). Milk fat was measured in a microhematocrit centrifuge and expressed as a fraction of the total volume.

Calculations and statistics. The nonparametric Mann-Whitney test was used for comparison of groups, and results are accordingly given as medians and ranges. Values of $p<0.05$ were considered significant.

\section{RESULTS}

Milk from streptozocin-diabetic rats receiving no therapeutic intervention after parturition was compared with that of diabetic animals receiving insulin and control animals.

Milk volume. The volume of milk produced (Fig. 1) was significantly reduced in untreated diabetic rats compared with both controls and insulin-treated diabetic rats. This difference between the groups was significant on all days measured, except when the untreated group was compared with the insulin-treated diabetic group on $\mathrm{d} 1$.

$E G F$ in milk. The concentration of EGF was significantly decreased on all days measured in milk from the untreated diabetic dams compared with the controls (Fig. $2 a$ ). The difference in the total output of EGF (Fig. $2 b$ ) was even more pronounced when the untreated diabetic group was compared with both the insulin-treated diabetic and the control groups on the days measured, because the low volume of milk became additive to the reduced concentration of EGF. The total output of EGF in milk of the controls and insulin-treated diabetic rats both reached maximum values on $d 16$. In contrast, the total output of EGF from the untreated diabetic rats remained constantly low

\section{Milk volume}

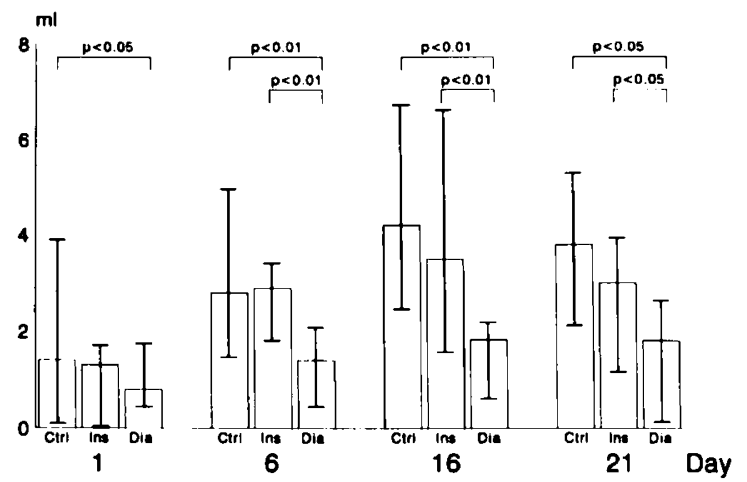

Fig. 1. Milk volume obtained on $\mathrm{d} 1,6,16$, and 21 ( $x$ axis) from control (Ctrl), insulin-treated diabetic (Ins), or untreated diabetic (Dia) rats. Bars indicate the median values and vertical lines the ranges. $n=$ 34. (a) EGF concentration

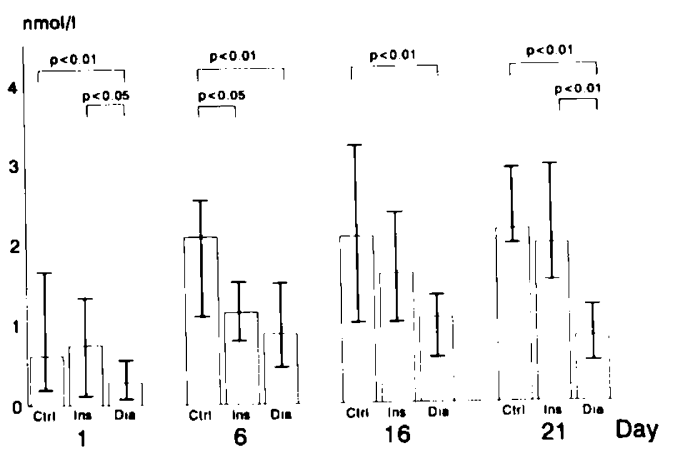

(b)

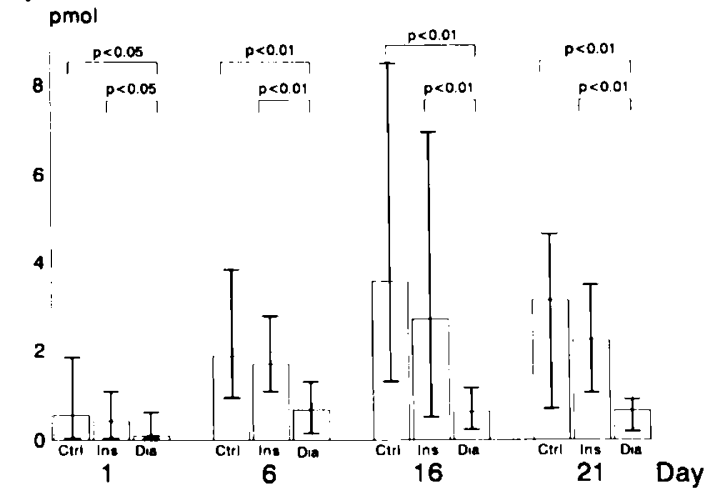

(c) EGF - total protein ratio

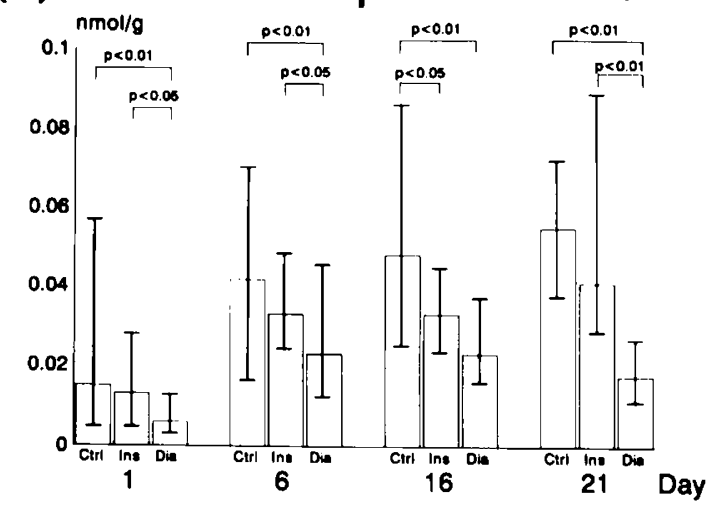

Fig. 2. $a$, Concentration of EGF in infranatant fluid of rat milk; $b$, total output of EGF in milk; and $c$, the EGF-total protein ratios expressed for milk obtained on d 1, 6, 16, and 21 ( $x$ axes) from control (Ctrl), insulin-treated diabetic (Ins), or untreated diabetic (Dia) rats. Bars indicate the median values and vertical lines the ranges. $n=34$.

throughout the lactation period. Expressed as the EGF-total protein ratio (Fig. $2 c$ ), a significant reduction was observed in the milk from the untreated diabetic group compared with the insulin-treated and control groups.

Haptocorrin, total protein, and fat in milk. In contrast to the reduced content of EGF in milk, the concentration of haptocorrin (Fig. $3 a$ ) was not decreased in milk from the diabetic rats. On $\mathrm{d} 16$ of lactation, the concentration of haptocorrin decreased in milk from the controls, but this decrement was absent at the same time point in milk from both the diabetic and insulintreated diabetic groups. The concentration of total protein (Fig. $3 b$ ) in milk was not significantly different between the groups and did not change with time. Furthermore, no difference was 
(a) Haptocorrin concentration

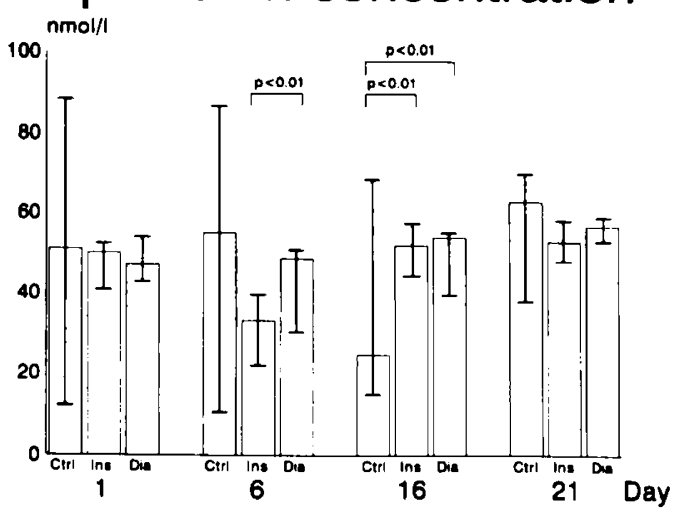

(b)

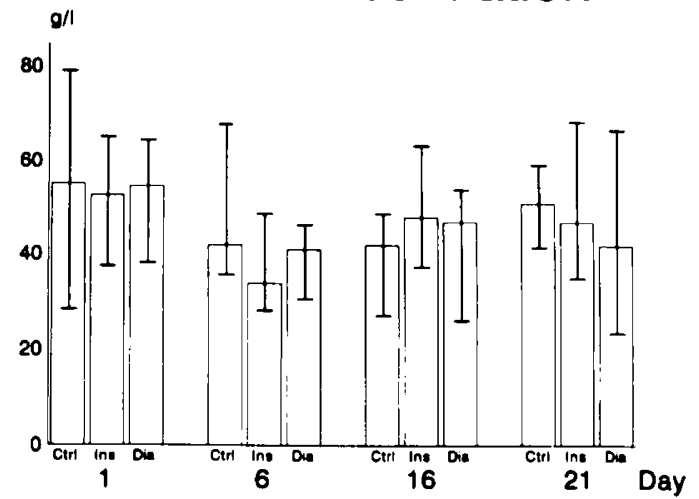

Fig. 3. Concentration of haptocorrin $(a)$ and total protein $(b)$ in infranatant fluid of rat milk obtained on d 1, 6, 16, and 21 of lactation ( $x$ axes) from control $(C t r l)$, insulin-treated diabetic (Ins), or untreated diabetic (Dia) rats. Bars indicate the median values and vertical lines the ranges. $n=34$.

found in the percentages of fat between any of the groups (data not shown).

Litter size and body weight. At parturition, no macroscopically visible malformations or difference in the number of pups was observed between the groups. Body weights were also comparable. However, in the untreated diabetic group, the weights of the pups were significantly reduced on d 6,16, and 21 (Fig. 4a). On the basis of head-to-tail length (Fig. 4b), pups of the untreated diabetic dams were significantly shorter on $d 16$ and 21 than pups of the control and insulin-treated diabetic groups. The pups of the untreated dams had a smaller corpus, relatively large paws, and less hairy skin than the pups from the insulin-treated and control dams (Fig. 5).

Eyelid opening and tooth eruption. On d 16 of lactation, all pups of the control rats and the insulin-treated diabetic rats had opened their eyelids. However, only $24 \%$ of the pups of the untreated diabetic dams had open eyelids on $d 16$. In contrast, no difference was observed in the time of tooth eruption, this being completed at the same time in all three groups of rats $(d$ 13).

\section{DISCUSSION}

In this study, we found that untreated diabetic rats produce significantly less milk with a significantly decreased concentration of EGF than insulin-treated diabetic rats and control rats. In contrast, the concentration of total protein, the concentration of the cobalamin-binding protein haptocorrin, and the milk fat percentage were not affected by the insulin deficiency. (a)

\section{Pup weight}

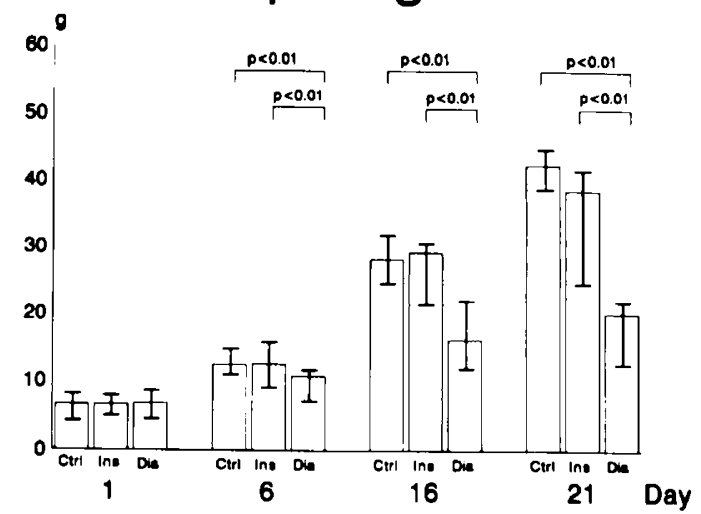

(b) Head - tail length

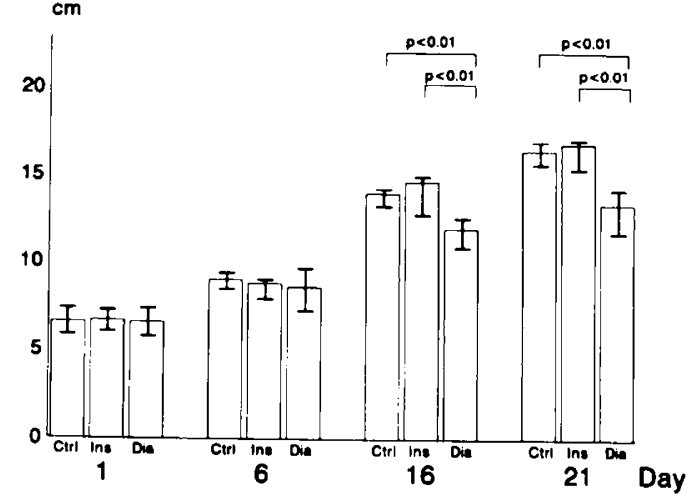

Fig. 4. The weight ( $a$ ) and the head-to-tail length $(b)$ of pups on $\mathrm{d} 1$, 6,16 , and 21 of lactation ( $x$ axes) from control $(C t r l)$, insulin-treated diabetic (Ins), or untreated diabetic (Dia) dams. Bars indicate median values and vertical lines ranges.

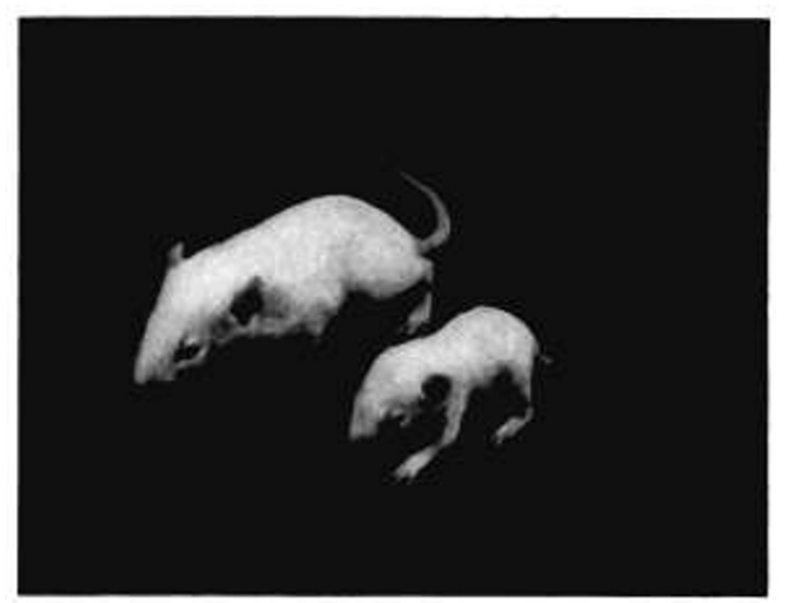

Fig. 5. Two 16-d-old pups, one from a control dam (left) and the other from an untreated diabetic dam (right). Pups of the latter group had delayed eyelid opening and reduced body weight and head-to-tail length but no difference in the time of tooth eruption compared with pups of controls. 
It has previously been demonstrated that insulin deficiency in experimental diabetes causes a decrease in the synthesis of EGF in the submandibular glands $(14,15)$. These findings were observed only after several weeks of untreated diabetes. The decrement in milk EGF in the present study was measured within a period of only $24 \mathrm{~h}$ of insulin deficiency.

Insulin treatment restored the values of milk yield and the concentration of EGF to values comparable to those of the controls and thus normalized the total output of EGF. This indicates that insulin treatment reverses the decrement in the secretion of EGF from the mammary glands in accordance with previous findings in the submandibular glands of diabetic mice (14), thus indicating that the alterations in the secretion of EGF are caused by the diabetes directly and that they are not effects secondary to the streptozocin used to induce the diabetic state (14).

In the present study, untreated diabetes caused no decrease in the concentration of total protein or haptocorrin, suggesting that diabetes impairs the secretion of selected proteins such as EGF, rather than playing a role in the secretion of all proteins into milk. The measured course of the concentration of haptocorrin in milk from the controls during the lactation period in the present study is in accordance with our previous report (23). However, the concentration of haptocorrin in milk from the diabetic and insulin-treated diabetic groups did not decrease to a level comparable to that of the controls on $\mathrm{d} 16$ of lactation, and the former groups had significantly higher concentrations of haptocorrin on this day in comparison with the controls. Haptocorrin is synthesized only in single, scattered cells in the tubuloalveolar glands (23), whereas the immunoreactivity of EGF has been observed at the luminal border of almost all alveolar cells of the mammary glands $(8,24)$. Thus, the cells capable of the synthesis of haptocorrin do not seem to be affected by the deficiency of insulin in contrast to the cells synthesizing EGF. These results indicate that the content of EGF in milk is dependent on insulin, which is in concert with our previous findings that daily insulin treatment of normal, lactating rats in a dose not causing hypoglycemia increases the concentration of EGF without any effects on the volume of milk collected (24). However, an influence of hyperglycemia per se on the content of EGF in milk of diabetic rats cannot be excluded.

In a previous study with rats, body weight gain of pups from untreated diabetic dams was reduced during the first $10 \mathrm{~d}$ of lactation, which was related to a poor lactational performance (25). The latter was suggested to correlate with an impaired pituitary secretion of prolactin and a poor development of the mammary glands (25). This seems consistent with the findings in the present study that the volume of milk collected from insulin-deficient rats was significantly reduced compared with the insulin-treated and control rats. In treated diabetic women, the volume of milk obtained at suckling was reduced to half the volume obtained from control women (3). A decrease in the milk yield has also been observed in ewes with mild hyperglycemic alloxan-induced diabetes, but, in contrast to the present report, the content of milk fat from the ewes was also significantly decreased (26).

The present induction of diabetes by streptozocin was performed with a sufficient interval between the drug injection and mating to prevent any direct effects of the drug on the fertilized ovum (27). Primarily a fourth group of diabetic rats that were untreated during pregnancy were included in the experimental series, but these rats had to be excluded from the study because they were unable to lactate even though they had a full-term delivery with offsprings comparable to the controls.

The number, the weight, and the head-to-tail length of the pups were comparable in the three groups of rats at the time of delivery. However, in accordance with a previous report (26), the body weight gain of the pups from the untreated diabetic rats was significantly reduced in the course of the lactation period. In these pups, a notable delayed time of eyelid opening was observed, whereas no difference was observed in the time of tooth eruption. This altered pattern of developmental events in the pups may relate both to undernourishment and to the reduced amounts of EGF in the milk. Early neonatal treatment of newborn rats with excessive amounts of EGF markedly accelerates the time of eyelid opening (28). The incisor eruption is accelerated only to a minor degree (28), probably because of a more prolonged and earlier initiation of this event. Therefore, the observation in the present paper that pups of dams with a decreased supply of EGF in milk had delayed time of eyelid opening might support a physiologic role for EGF in milk in connection with the postnatal development. However, to prove a potential linkage demands a final study with normalization of the time of eyelid opening by EGF treatment of the pups.

In conclusion, the present paper has shown that untreated diabetes in rats results in significantly reduced amounts of EGF in milk. The decrement in the milk EGF concentration seems to be selective in comparison to total protein in milk, which was unaltered by the diabetic state. The decrease in the concentration of EGF was restored by insulin treatment of the diabetic rats.

Acknowledgments. The authors thank Grazyna Hahn and Birgit W. Mortensen for their technical assistance.

\section{REFERENCES}

1. Jovanovic L, Peterson CM 1980 Management of the pregnant insulin-dependent diabetic woman. Diabetes Care 3:63-68

2. Gabbe SG, Quilligan EJ 1981 General obstetric management of the diabetic pregnancy. Clin Obstet Gynecol 24:91-103

3. Miyake A, Tahara M, Koike K, Tanizawa O 1989 Decrease in neonatal suckled milk volume in diabetic women. Eur J Obstet Gynecol Reprod Biol 33:4953

4. Read LC, Upton FM, Francis GL, Wallace JC, Dahlenberg GW, Ballard FJ 1984 Changes in the growth-promoting activity of human milk during lactation. Pediatr Res 18:133-139

5. Beardmore JM, Richards RC 1983 Concentrations of epidermal growth factor in mouse milk throughout lactation. J Endocrinol 96:287-292

6. Raaberg L, Nexø E, Tollund L, Poulsen SS, Christensen SB, Christensen MS 1990 Epidermal growth factor activity in rat milk. Regul Pept 30:149-157

7. Carpenter $G 1980$ Epidermal growth factor is a major growth-promoting agent in human milk. Science 210:198-199

8. Brown CF, Teng CT, Pentecost BT, DiAugustine RP 1989 Epidermal growth factor precursor in mouse lactating mammary gland alveolar cells. Mol Endocrinol 3:1077-1083

9. Koldovsky O, Bedrick A, Rao RK 1991 Role of milk-borne prostaglandins and epidermal growth factor for the suckling mammal. J Am Coll Nutr 10:17-23

10. Cohen $S 1962$ Isolation of a mouse submandibular gland protein accelerating incisor eruption and eyelid opening in tie newborn animal. J Biol Chem 237:155-162

11. Falconer J 1987 Oral epidermal growth factor is trophic for the stomach in the neonatal rat. Biol Neonate 52:347-350

12. Puccio $F$, Lehy $T 1988$ Oral administration of epidermal growth factor in suckling rats stimulates DNA synthesis in fundic and anstral gastric mucosa as well as in intestine mucosa and pancreas. Regul Pept 20:53-64

13. Cross I, Dynia DW, Rooney SA, Smart DA, Warshaw JB, Sissom JF, Hoath SB 1986 Influence of epidermal growth factor on fetal rat lung development in vitro. Pediatr Res 20:473-477

14. Kasayama S, Ohba Y, Oka T 1989 Epidermal growth factor associated with diabetes mellitus. Proc Natl Acad Sci USA 86:7644-7648

15. Hwang DL, Lev-Ran A 1990 Epidermal growth factor in serum, urine, submandibular glands and kidneys of diabetic mice. Life Sci 47:679-685

16. de Diego JG, Rouiller DG, Gorden P, Carpenter JL 1992 Epidermal growth factor receptor internalization and biosynthesis in the diabetic rat. Exp Cell Res 200:77-82

17. Sissom JF, Stenzel WK, Warshaw JB 1987 Decreased binding of epidermal growth factor in placentas from streptozotocin-diabetic rats. J Clin Invest 80:242-247

18. Okamoto M, Kahn CR, Maron R, White MF 1988 Decreased autophosphorylation of EGF receptor in insulin-deficient diabetic rats. Am J Physiol 254:E429-E434

19. Rash R 1979 Control of blood glucose levels in the streptozotocin diabetic rat using a long-acting heat-treated insulin. Diabetologia 16:185-190

20. Jørgensen PE, Rasmussen TN, Olsen PS, Raaberg L, Poulsen SS, Nexø E 1990 Renal uptake and excretion of epidermal growth factor from plasma in the rat. Regul Pept 28:273-280 
21. Smith PK, Krohn RI, Hermanson GT, Mallia AK, Garner FH, Provenzano MD, Fujimoto EK, Goeke NM, Olson BJ, Klenck DC 1985 Measurement of protein using bicinchoninic acid. Anal Biochem 150:76-85

22. Gottlieb C, Law KS, Wasserman LR, Herbert W 1965 Rapid charcoal assay for intrinsic factor (IF), gastric juice unsaturated B-12, antibody to IF and serum unsaturated B-12 binding capacity. Blood 25:875-884

23. Raaberg L, Nexø E, Poulsen SS, Tollund L 1989 Cobalamin and its binding in rat milk. Scand J Clin Lab Invest 49:529-535

24. Thulesen J, Raaberg L, Nexø E, Madsen EL, Poulsen SS 1993 Epidermal growth factor in mammary glands and milk from rats: the influence of insulin. Diabetes Res Clin Pract 21:11-18
25. Ikawa H, Irahara M, Matsuzaki T, Saito S, Sano T, Aono T 1992 Impaired induction of prolactin secretion from the anterior pituitary by suckling in streptozotocin-induced diabetic rat. Acta Endocrinol (Copenh) 126:167-172

26. Leenanuruksa D, McDowell GH 1988 Experimental diabetes in lactating sheep: effects of alloxan on plasma insulin, glucose, glucose kinetics and milk characteristics. Aust J Biol Sci 41:223-229

27. Farrell PM, Engle MJ, Frantz ID, Goldman AS, Kalkhoff R, Kemnitz JW, Perleman R, Stern JS, Susa JB 1982 Complications of pregnancy and fetal development. Diabetes 31:89-94

28. Hoath SB 1986 Treatment of the neonatal rat with epidermal growth factor: differences in time and organ response. Pediatr Res 20:468-472 